\title{
An assessment of the perceived association between oral health and pregnancy outcomes in a sample of surveyed doctors in Port Harcourt Nigeria
}

\author{
Braimoh Omoigberai Bashiru*, Ilochonwu Nzube Anthony \\ Department of Preventive Dentistry, Faculty of Dentistry, College of Health Sciences, University of Port Harcourt, Choba Port Harcourt, \\ Rivers State, Nigeria
}

\section{Email address:}

omoigberai.braimoh@uniport.edu.ng (O. B. Braimoh),nzube.ilochonwu@uniport.edu.ng (N. A. Ilochonwu)

\section{To cite this article:}

Braimoh Omoigberai Bashiru, Ilochonwu Nzube Anthony. An Assessment of the Perceived Association between Oral Health and Pregnancy Outcomes in a Sample of Surveyed Doctors in Port Harcourt Nigeria. European Journal of Preventive Medicine.

Vol. 2, No. 6, 2014, pp. 95-98. doi: 10.11648/j.ejpm.20140206.13

\begin{abstract}
Background: Misconceptions exist on the safety of dental care during pregnancy. The aim of the study was to evaluate the knowledge of medical practitioners on the relationship between oral health and pregnancy outcomes. Subjects and Methods: A cross-sectional survey involving resident doctors at the University of Port Harcourt Teaching Hospital, Rivers State Nigeria. Data was collected using self-administered questionnaires and analyzed using IBM SPSS (New York, USA) statistics version 20.0. Frequency statistics and bivariate analysis were done and Chi-square test was used to test for statistical significance at the critical value $\mathrm{p}<0.05$. Results: A total of 138 medical practitioners made up of $90(65.2 \%)$ males and 48 (34.8\%) females completed the questionnaire. Eighty five (62\%) of the subjects were less than 35 years and $76(55 \%)$ had practiced for less than 10 years. Approximately $53 \%$ of the subjects would advise patients to visit dentist during pregnancy. The sources of information were medical journal, 58\%; medical curriculum, 46\%; clinical teaching, 52\% and internet, 35\%. The majority 117 (85\%) of the participants believed there was a possible connection between oral health and pregnancy outcomes, whereas 86 (62.3\%) were ignorant that it was safe to carryout dental treatment during pregnancy. Gender, age and years of practice were significant determinant for advising dental visits. Conclusion: Approximately half of the medical practitioners would advise dental visits during pregnancy. Though majority of the participants were aware of the possible connection between oral health and pregnancy outcomes, they were ignorant of the impact of oral diseases on pregnancy outcomes and safety of dental care during pregnancy.
\end{abstract}

Keywords: Dental Visit, Medical Practitioners, Pregnancy Outcomes, Prenatal Care

\section{Introduction}

There has been increasing interest on the association between pregnancy outcomes and oral health. Oral diseases may impact negatively on pregnancy outcomes resulting in preterm birth, low birth weight and preterm low birth weight $[1,2]$. Preterm low birth weight, account for $75 \%$ of perinatal deaths and about half of all long-term neurological complications. About $10 \%$ of the births in the United States occur before 37 weeks of gestation, and the rate of premature delivery has increased over the years [3]. Interestingly, about half the mothers delivering preterm infants have no known risk factors [4].

In a systematic meta-analytic review of 17 articles, Vergnes and Sixou reported a statistically significant association between periodontitis and adverse pregnancy outcomes [5]. Umoh et al., [6] in a Nigerian study to investigate the effect of maternal periodontal status on birth weight, reported low birth weight deliveries which were significantly associated with poor periodontal status and concluded that periodontal treatment was effective in preventing low birth weight deliveries. It has been reported that controlling plaque by brushing, flossing and professional prophylaxis, including scaling and root planing, help to achieve good oral health in pregnancy and prevent low birth weight [7]. Comprehensive prenatal health care should include an assessment of oral health, but this is often overlooked [8]. Pregnancy is a time when women may be more motivated to make healthy changes and medical practitioners can address maternal oral issues, potentially reducing the risk of preterm birth and childhood caries 
through oral disease prevention, diagnosis, early management, and dental referral [9].

Poor utilization of dental services during pregnancy has been reported by various studies in the literature [10-12]. In Nigeria, the reported utilization of dental services during pregnancy is between $5-20 \%[13,14]$. There are a number of barriers to the utilization of dental services during pregnancy, these include; difficulty in finding a dentist, low priority given to dental care, lack of insurance, misconception about safety and appropriateness of dental care during pregnancy and lack guidance during prenatal care $[15,16]$. Lack of general medical practitioner's knowledge of oral disease has been shown to contribute to delays in referral and treatment. The lack of anticipatory guidance during prenatal care may not be unconnected with poor knowledge of possible association between oral health and pregnancy outcomes among doctors.

There is paucity of data on physicians' knowledge of the associations between oral health and pregnancy outcomes in Nigeria. The aim of this study therefore, was to access the willingness of doctors to advise dental care during pregnancy and evaluate their knowledge on the relationship between oral health and pregnancy outcomes.

\section{Subjects and Methods}

This descriptive cross-sectional survey involved resident doctors at the University of Port Harcourt Teaching Hospital, Rivers State Nigeria. Well structured, pretested, selfadministered questionnaire was used for data collection. The study participants were approached at their duty posts (clinics), and informed consent obtained before administering the questionnaire. The questionnaire was completed and returned immediately by the participants, while those busy with patients were allowed to complete the questionnaires at their free time and retrieved subsequently. Information on the socio-demographic characteristics of the study subjects was obtained. These included age in years at last birth day, gender and years of practice. Participants were asked whether or not they would advise patient to visit dentist during pregnancy or delay visiting dentist to after pregnancy. Questions that bothered on doctors' perceptions of the association between pregnancy and oral health and source of such information were also asked.

Collected data were compiled, organized and recorded in the computer SPSS files version 20.0 for analysis. Frequency statistics and bivariate analysis were done and Chi-square test was used to test for statistical significance at the critical value $\mathrm{p}<0.05$.

\section{Results}

A total of 138 resident doctors made up of 90 (65.2\%) males and $48(34.8 \%)$ females completed the questionnaire. Eighty five $(62 \%)$ of the subjects were less 35 years and 76 $(55 \%)$ had practiced for less than 10 years (Table 1$)$. The doctors' perception of when to advise dental visit is presented in (Table 2). Majority $110(80 \%)$ of the subjects would advise patients to delay seeing a dentist until after pregnancy, whereas $73(53 \%)$ would advise patients to visit dentist during pregnancy.

Table 1. Frequency and percent distribution of demographic information of the subjects.

\begin{tabular}{lll}
\hline Variables & Number & Percent (\%) \\
\hline Age in years & & \\
$<35$ & 85 & 61.6 \\
$\geq 35$ & 53 & 38.4 \\
Gender & & \\
Male & 90 & 65.2 \\
Female & 48 & 34.8 \\
Years of Practice & & \\
$<10$ & 76 & 55.1 \\
$\geq 10$ & 62 & 44.9 \\
\hline
\end{tabular}

Table 2. Respondents response Number and percent distribution of advising patient to visit the dentist during pregnancy or delay dental visit until after pregnancy.

\begin{tabular}{lll}
\hline Questions on dental visit & Number & Percent (\%) \\
\hline When Will you advise dental visit & & \\
Yes & 73 & 52.9 \\
No & 65 & 47.1 \\
Will you advise patient to delay dental visit & & \\
until after pregnancy & & \\
Yes & 110 & 79.7 \\
No & 28 & 20.3 \\
\hline
\end{tabular}

Table 3. Source of information of the association between oral health and pregnancy.

\begin{tabular}{lll}
\hline Source of information & Yes $\mathbf{( \% )}$ & No $(\mathbf{\%})$ \\
\hline The internet & 35 & 65 \\
Television & 31 & 69 \\
Books, magazines and pamphlet & 42 & 58 \\
Medical Journal & 58 & 42 \\
Medical curriculum & 46 & 54 \\
Clinical teaching & 52 & 48 \\
\hline
\end{tabular}

Table 4. Bivariate analysis of knowledge statement and advising dental visit during pregnancy.

\begin{tabular}{llll}
\hline Knowledge statement & $\begin{array}{l}\text { Percent positive response } \\
(\mathbf{N ~ \& ~ \% , ~ N = 1 3 8 ) ~}\end{array}$ & $\begin{array}{l}\text { Advise visiting } \\
\text { the dentist (\%) }\end{array}$ & $\begin{array}{c}\text { Did not advise visiting the } \\
\text { dentist (\%) }\end{array}$ \\
\hline $\begin{array}{l}\text { Do you think there is possible connection between } \\
\text { the health of the teeth and gum and pregnancy? }\end{array}$ & $117(84.8)$ & 67 \\
$\begin{array}{l}\text { Do you think pregnancy increases the tendency of } \\
\text { the gum to bleed or swell? }\end{array}$ & $65(47.1)$ & 58 & 42 \\
$\begin{array}{l}\text { Do you think tooth and gum problems may affect } \\
\text { pregnancy outcomes? }\end{array}$ & $63(45.7)$ & 59 & 41 \\
$\begin{array}{l}\text { Do you believe that dental problems can be treated } \\
\text { safely in pregnancy? }\end{array}$ & $52(37.7)$ & 72 & 0.03 \\
\hline
\end{tabular}


The source of information of the association between oral health and pregnancy is shown in Table 3 . The major source of information was medical journal (58\%); other sources are Medical curriculum, 46\%; clinical teaching, 52\%; internet, $35 \%$; television, $31 \%$; books and magazines $42 \%$.

Table 4 shows percentage distribution of the knowledge statement and bivariate analysis of knowledge statement and advising dental visit during pregnancy. Though 117 (85\%) of the participants believed there was a possible connection between oral health and pregnancy outcomes, 73 (52.9\%) were ignorant that pregnancy increases the tendency of the gum to bleed or swell, $75(54.3 \%)$ did not believe that tooth and gum problems may affect pregnancy outcomes and 86 $(62.3 \%)$ were not aware dental care could be carried out safely in pregnancy. Most of the subjects who agreed with the knowledge statements were more likely to advise dental visits and this was significant for all knowledge statement. In addition, females, older participants and those that have practiced for more than 10 years were more likely to advise dental visits.

\section{Discussion}

Oral diseases are of public health interest and are preventable. Early detection of oral diseases facilitates prompt treatment and restoration to health and function. Delay in presentation and/or referral has a significant effect on the associated morbidity and mortality. The role played by medical practitioner to improve the oral health of the population depends on his knowledge about oral disease and their effect on general health. There is a misconception among medical practitioners that provision of dental care during pregnancy is not safe. This misconception was reflected in the present study; about $80 \%$ of medical practitioners interviewed in this study reported they would advise delay of dental visits until after delivery. Available evidence shows that dental care can be provided at any time during pregnancy allowing pregnant women to achieve an optimal level of oral health throughout pregnancy $[2,17,18]$. Therefore, advising dental visits during pregnancy is recommended.

Participants who agreed that there was connection between oral health and pregnancy, those who believed that dental problems could be treated safely in pregnancy as well as those who were aware that pregnancy increases the tendency of the gingiva to bleed or swell and that oral diseases could affect pregnancy outcomes were significantly more likely to advise dental visits during pregnancy. These findings are similar to that of Al-Habashneh et al., [19] who reported that better knowledge and awareness is important in understanding the benefit of utilizing dental services during pregnancy.

In this study $85 \%$ of the participants responded 'positively' to the question 'Do you think there is possible connection between the health of the teeth and gum and pregnancy?'.This is higher than $50 \%$ of positive response obtained in a Jordanian study [19]. Difference in the study population may be responsible for this variation. The respondents in this study were doctors undergoing postgraduate medical training in a tertiary health institution compared to the Jordanian study where the respondents were doctors working in maternities, comprehensive health centers and other hospitals. Studies have suggested that treatment of periodontal disease in pregnancy is feasible and may reduce the risk of preterm birth [6,7]. Only one-third of the sample agreed with this statement. Similarly, more than half of the doctors did not recognize that pregnancy could cause the gingiva to swell and bleed; neither could they identify oral diseases as risks factors for pregnancy outcomes (preterm birth, low birth weight and preterm low birth weight). This is an indication of gap in knowledge of the relationship between oral health and pregnancy outcomes among the respondents. This gap can be bridged by revising university curriculum at both undergraduate and postgraduate training levels, carrying out national awareness campaign and continuing medical examination for practicing doctors.

The major sources of information of the association between oral health and pregnancy in the present study were found to be medical journal, clinical teaching and medical curriculum. Previous study [19] had reported internet as the main source of information of the association between oral health and pregnancy among medical practitioners. The accessibility, affordability and availability of internet services among the study population may be responsible for the difference. In addition, computer ownership among health care professionals and students in Nigeria has been reported to be low [20,21]. Poor utilisation of internet services among Nigerians has also been reported [22, 23].

\section{Conclusion}

Approximately half of the medical practitioners would advise dental visits during pregnancy. Though majority of the participants were aware of the possible connection between oral health and pregnancy outcomes, they were ignorant of the impact of oral diseases on pregnancy outcomes and safety of dental care during pregnancy. Thus, the development of guidelines on oral care during pregnancy as part of routine ante-natal care is imperative. Prenatal care providers should be educated and encouraged to discuss the relationship between oral health and pregnancy outcomes with their patients and further advise them to visit dentists during pregnancy.

\section{References}

[1] Jeffcoat MK, Geurs NC, Reddy MS, Cliver SP, Goldenerg RL, Hauth JC. Periodontal infection and preterm birth: results of a prospective study. J Am Dent Assoc 2001;132:875-80.

[2] Offenbacher S, Katz V, Fertik G, Collins J, Boyd D, Maynor G, et al. Periodontal infection as a possible risk factor for preterm low birth weight. J Periodontol 1996;67:1103-13. 
[3] Slattery MM, Morrison JJ. Preterm delivery. Lancet 2002;300:1489-97.

[4] McCormick MC. The contribution of low birth weight to infant mortality and childhood morbidity. N Engl J Med 1985;312:82-90.

[5] Vergnes JN, Sixou M. Preterm low birth weight and maternal periodontal status: a meta-analysis. Am J Obstet Gynecol 2007;196:135.e1-7.

[6] Umoh AO, Ojehanon PI, Savage KO. Effect of maternal periodontal status on birth weight. Eur $\mathrm{J}$ Gen Dent $2013 ; 2: 158-62$

[7] Mills LW, Moses DT. Oral health during pregnancy. MCN Am J Matern Child Nurs 2002;27:275-80.

[8] Allston AA. Improving women's health and perinatal outcomes: the impact of oral diseases. Baltimore, Md.: Women's and Children's Health Policy Center, 2002. Available from: http://www.jhsph.edu/wchpc/publications/. Accessed 2014 September 17].

[9] Kumar J, Samelson R, eds. Oral health care during pregnancy and early childhood: practice guidelines. New York, NY: New York State Department of Health, 2006. Available from: http://www.health.state.ny.us/publications/0824.pdf. Accessed 2014 October 9.

[10] Gaffield ML, Gilbert BJ, Malvitz DM, Romaguera R. Oral health during pregnancy: an analysis of information collected by the pregnancy risk assessment monitoring system. J Am Dent Assoc 2001;132:1009-16.

[11] Mangskau KA, Arrindell B. Pregnancy and oral health: utilization of the oral health care system by pregnant women in North Dakota. Northwest Dent 1996;75:23 - 8.

[12] Marchi KS, Fisher-Owen SA, Weindraub JA, Yu Z, Braveman PA. Most pregnant women in California do not receive dental care: findings from a population based study. Pub Health Rep 2010; 25: 831-42.
[13] Adeniyi AA, Ogunbanjo BO, Sorunke ME, Onigbinde OO, Agbaje MO, Braimoh M. Dental Attendance in a sample of Nigeria pregnant women. Nig Q J Hosp Med 2010;20:186-91.

[14] Bukar M, Audu BM, Adesina OA, Marupa JY. Oral health practices among pregnant women in North Eastern Nigeria. Nig J Clin Pract 2012;15:302-5

[15] Detman LA, Cottrel BH, Denis-Luque MF. Exploring dental care misconceptions and barriers in pregnancy. Birth 2010;37:318-24.

[16] Keirse MJ, Plutzer K. Women's attitudes to and perceptions of oral health and dental care during pregnancy. J Perinatal Med $2010 ; 38: 3-8$.

[17] American Dental Association: International workshop for classification of periodontal disease and conditions. Ann Periodontol 1999;4:1-112.

[18] Silk H, Douglass AB, Douglass JM, Silk L. Oral health during pregnancy. Am Fam Physician 2008;77:1139-44.

[19] Al-Habashneh R, Aljundi SH, Alwaeli HA. Survey of medical doctors' attitudes and knowledge of the association between oral health and pregnancy outcomes. Int $\mathrm{J}$ Dent Hygiene 2008;6:214-20.

[20] Ajuwon GA. Use of internet for health information by physicians for patients care in a teaching hospital in Ibadan Nigeria. Biomed Digital Lib 2006;12:3-12.

[21] Ayanbadejo PO, Sofola OO, Uti OG. Access to and use of computers among clinical dental students of the University of Lagos. Nig Dent J 2008;16:74-7.

[22] Ogunyade TO, Ibeagwam A. A survey of medical students computer use. The University of Lagos College of Medicine experience. Nig Q J Hosp Med 2005;15:116-8.

[23] Braimoh OB, Udeabor SE. Evaluation of Computer use and internet access among undergraduate medical students: Afri J Med Sci 2012;5:96-101. 